\title{
5
}

\section{Prevalence of Back Pain in Postmenopausal Osteoporosis and Associations with Multiple Spinal Factors}

\author{
Naohisa Miyakoshi, Michio Hongo and Yoichi Shimada \\ Department of Orthopedic Surgery, Akita University Graduate School of Medicine
}

Japan

\section{Introduction}

Back pain is considered to be most prevalent musculoskeletal pain, particularly in elderly populations (Woo et al., 2009). The existing literature suggests a prevalence of chronic back pain among the elderly ranging from $7 \%$ to $58 \%$ (Edmond \& Felson, 2000; Jacobs et al., 2006; Lavsky-Shulan et al., 1985; March et al., 1998), with differences attributable to a lack of concordance in terms of age stratification, definition, and methodology, but with consistently much higher rates in women than men (Jabobs et al., 2006; Woo et al., 2009). The reason why back pain is common among elderly women may be related to osteoporosis. As lower bone mineral density (BMD) and the rapid decline in BMD following menopause in women result in a greater prevalence of osteoporosis and vertebral fractures compared to men, osteoporosis is likely to represent a major cause of back pain among elderly women. However, although osteoporosis may be an underlying cause of back pain, especially in postmenopausal elderly women, the prevalence of back pain in this group has not been fully investigated.

Although back pain in osteoporosis is often attributed to vertebral fractures (Nevitt et al., 1998; Ulivieri, 2007), the intensity of pain is not always influenced by fracture status (Hübscher et al., 2010). Liu-Ambrose et al. demonstrated that osteoporotic women may experience back pain without a concomitant history of vertebral compression fractures (LiuAmbrose et al., 2002). The cause of back pain in osteoporosis thus seems likely to be related to multiple factors.

Spinal alignment and mobility are important factors for spinal function and may be related to back pain. Loss of lumbar lordosis correlates well with the incidence of chronic low back pain in adults (Djurasovic \& Glassman, 2007; Glassman et al., 2005). Patients with a less mobile spine may show more severe symptoms. In addition, we have previously demonstrated that back extensor strength is significantly associated with spinal mobility (Miyakoshi et al., 2005). However, to the best of our knowledge, simultaneous assessment of back pain and multiple spinal factors such as vertebral fractures, spinal alignment and mobility, as well as back extensor strength, has not yet been investigated in patients with osteoporosis.

The objectives of this study were thus: 1) to determine the prevalence of back pain in patients with postmenopausal osteoporosis who visited their practitioner; and 2) to evaluate 
associations of back pain and vertebral fractures, spinal alignment, mobility, and back extensor strength in these patients.

\section{Materials and methods}

\subsection{Patients}

A total of 174 consecutive women with postmenopausal osteoporosis aged 50 years and older who visited their practitioner (orthopedic clinic) were enrolled in the present study. All these patients were the same patients who enrolled in our previous study assessing back extensor strength and quality of life (QOL) (Miyakoshi et al., 2007). Osteoporosis was diagnosed according to the criteria proposed by the Japanese Society for Bone and Mineral Research (JSBMR) (Orimo et al., 2001). Briefly, patients with BMD less than $70 \%$ of the young adult mean BMD or with fragility fracture were diagnosed as having osteoporosis. All participants were asked whether they had clinically relevant back pain, and BMD, number of vertebral fractures, angle of kyphosis, range of motion (ROM) of the thoracic and lumbar spine, and back extensor strength were evaluated. These variables were compared between subjects with back pain (BP group) and those without back pain (non-BP group). In the BP group, associations between intensity of back pain and other measured variables were further evaluated.

Exclusion criteria were as follows: 1) women with a history of metabolic bone disease, malignancy, or recent antiosteoporotic treatment (with exception of calcium); 2) patients with hip fracture; 3) patients who could not lie in a prone position; 4) chronic use of glucocorticoids; 5) a concomitant illness that would substantially influence the daily living (e.g., chronic pulmonary disease, asthma, angina, chronic congestive heart failure, stroke, blindness, etc.); 6) other diseases that might cause back pain (e.g., scoliosis, lumbar spondylolisthesis, lumbar disc disease, etc.); and 7) patients with documented vertebral fracture within the last 6 months. Patients enrolled in the present study thus showed chronic back pain that was not attributable to a fresh vertebral fracture.

\subsection{Definition of clinically relevant back pain}

Back pain was considered clinically relevant if the participant answered that pain had been moderately to severely bothersome, or if the participant needed any medical treatment (Miyakoshi et al., 2010; Nevitt et al., 1998). In this study, the definition of back was not limited to the narrow sense of the upper and middle back, and low back was also included, as patients with osteoporosis often complain of pain affecting both definitions and differentiating between these seems difficult (Satoh et al., 1988).

\subsection{Evaluation of back pain intensity}

Intensity of back pain was evaluated using the pain domain score of the Japanese Osteoporosis QOL Questionnaire (JOQOL) (Table 1) (Kumamoto et al., 2010; Takahashi et al., 2000); as all questions for this score are limited to back pain, all domain scores show significant correlations on test and retest (Kendall's $\tau=0.691-0.818$ ) (Kumamoto et al., 2010) and the score can be used as a continuous variable to evaluate correlations with other measured variables. The pain domain score of JOQOL contains 5 questions. Scores for each item range from 0 to 4 , for a full score of 20. Pain intensity indicated in this study was calculated as 20 - estimated pain domain score of JOQOL. The pain intensity evaluated in this study thus ranged from 0 (no pain) to 20 (worst pain). 


\begin{tabular}{lc}
\hline \multicolumn{1}{c}{ Question } & Score (points) \\
\hline How often have you had back or low back pain in the & \\
last week? & 4 \\
Never & 3 \\
1. 1 day per week or less & 2 \\
2. 2-3 days per week & 1 \\
3. 4-6 days per week & 0 \\
4. Every day & \\
If you have had back pain or low back pain, for how & \\
long did you have it in the daytime? & 4 \\
1. No pain & 3 \\
2. 1-2 hours & 2 \\
3. 3-5 hours & 1 \\
4. 6-10 hours & 0 \\
5. All day & \\
While you kept still, how severe was your back or low & \\
back pain? & 4 \\
1. No pain & 3 \\
2. Mild & 2 \\
3. Moderate & 1 \\
4. Severe & 20 \\
5. Unbearable & \\
When you moved, how severe was your back or low & \\
back pain? & \\
1. No pain & \\
2. Mild & \\
3. Moderate & \\
4. Severe & \\
5. Unbearable & \\
Has the back or low back pain disturbed your sleep in & \\
the last week? & \\
1. Never & \\
2. Once & \\
3. Twice & \\
4. Every other night & \\
5. Almost every night & \\
\hline Total & \\
\hline
\end{tabular}

*Reference from Kumamoto et al., 2010.

Table 1. Pain domain questions of the Japanese Osteoporosis Quality of Life Questionnaire (JOQOL)*

\subsection{Evaluation of vertebral fractures}

$X$-rays of the thoracic and lumbar spine in lateral views with the patient in a neutral/lateral decubitus position were taken with a film-tube distance of $1 \mathrm{~m}$. Thoracic films were centered 
on T8, while lumbar films were centered on L3 (Miyakoshi et al., 2003b). Anterior, central, and posterior heights of each vertebral body from T4 to L5 were measured using calipers (Miyakoshi et al., 2003b). Coefficient of variation for this measurement was 2-3\% (Orimo et al., 1994). Vertebral fracture was considered present if at least one of the three height measurements (anterior, middle, or posterior) of one vertebral body had decreased by more than $20 \%$ compared with the height of the nearest uncompressed vertebral body (Orimo et al., 1994).

\subsection{Measurement of spinal kyphosis angles and ROMs}

Angles of kyphosis and ROM of the thoracic (T1-T12) and lumbar (L1-L5) spine were measured using a device for computerized measurement of surface curvature (SpinalMouse ${ }^{\circledR}$; Idiag, Volkerswill, Switzerland) in an upright position and at maximum flexion and extension (Kasukawa et al., 2010; Miyakoshi et al., 2005). Details regarding this device have been provided elsewhere (Post \& Leferink, 2004). The device consists of a mobile unit of 2 rolling wheels interfacing with a base station through telemetry. By sliding the mobile unit along the spinal curvature, sagittal spinal alignment is calculated and displayed on the computer monitor. Repeating this process with the patient in flexion and extension of the spine allows measurement of ROM (Post \& Leferink, 2004). SpinalMouse ${ }^{\circledR}$ delivers consistently reliable values for standing curvatures and ROM (Mannion et al., 2004; Post \& Leferink, 2004). Post and Leferink (Post \& Leferink, 2004) reported that interrater intraclass correlation coefficients (ICCs) for curvature measurement with SpinalMouse ${ }^{\circledR}$ were greater than 0.92. Mannion et al. (Mannion et al., 2004) reported that intrarater ICCs ranged from 0.82 to 0.83 , while interrater ICCs ranged from 0.81 to 0.86 . In addition, our previous studies have shown that thoracic and lumbar angles of kyphosis and spinal ROM measured using the SpinalMouse ${ }^{\circledR}$ correlate strongly with those measured on spinal radiography $(\mathrm{r}=0.804, \mathrm{r}=0.863$, and $\mathrm{r}=0.783$, respectively; $\mathrm{p}<0.0001)$ (Miyakoshi et al., 2004).

\subsection{Measurement of BMD}

BMD was measured by dual-energy X-ray absorptiometry (QDR-4500; Hologic, Bedford, MA). Measurements were obtained from anteroposterior projections of the second to fourth lumbar vertebrae, the femoral neck, and the whole body. The coefficient of variation for these variables in 5 corresponding measurements from 5 normal volunteers was less than 1.5\% (Miyakoshi et al., 2007).

\subsection{Measurement of back extensor strength}

Isometric back extensor strength in prone position was measured using a strain-gauge dynamometer (Digital Force Gauge DPU-1000N; IMADA, Toyohashi, Japan) as previously described (Hongo et al., 2007; Limburg et al., 1991; Miyakoshi et al., 2005). Subjects were allowed one warm-up trial, followed by three successive maximal effort trials separated by 60 -s rest periods (Hongo et al., 2007). Maximal force among the three trials was selected and documented. Coefficient of variation for this measurement was 2.3\% (Limburg et al., 1991).

\subsection{Data analysis}

All data are presented as mean and standard deviation (SD). Statistical analysis was performed using StatView version 5.0 software (Abacus Concepts, Berkeley, CA). Statistical 
differences between groups were compared using an unpaired t-test. Logistic regression analysis was used for analyzing significant risk factors for back pain. Correlations between pain intensity and other measured variables were analyzed using Pearson's correlation coefficient and simple regression analysis. Further analyses using multiple regression were conducted to determine which variables best correlated with back pain. Values of $\mathrm{P}<0.05$ were considered statistically significant.

\section{Results}

In this study, among 174 patients with postmenopausal osteoporosis, 159 patients $(91.4 \%)$ complained of back pain. Mean values for age and measured variables in the BP and non-BP groups are listed in Table 2. No significant differences were apparent between BP and non$\mathrm{BP}$ groups with regard to age, BMDs, number of vertebral fractures, angles of thoracic and lumbar kyphosis, and thoracic and lumbar ROMs. However, back extensor strength was significantly lower in the BP group than in the non-BP group. Similarly, when univariate logistic regression analysis was performed with the presence of back pain as a dependent variable and the other estimated variables as independent variables, only back extensor strength was identified as an index significantly associated with the presence of back pain (Table 3).

In patients with back pain, correlations between pain intensity and measured variables were evaluated. Pain intensity showed a significant positive correlation with the number of vertebral fractures, and negative correlations with lumbar spinal ROM and back extensor strength (Table 4). However, no significant correlations were observed between pain intensity and age, BMDs of all measured sites, angles of thoracic and lumbar kyphosis, or thoracic spinal ROM. Based on these results, number of vertebral fractures, lumbar spinal ROM, and back extensor strength were selected as independent variables for multiple regression modeling of pain intensity. Multiple regression analysis for pain intensity revealed lumbar spinal ROM and back extensor strength as significantly associated with pain intensity (Table 5).

\begin{tabular}{lccc}
\hline & $\mathrm{BP}(\mathrm{n}=159)$ & Non-BP $(\mathrm{n}=15)$ & $P$ \\
\hline Age (years) & $67.8 \pm 6.5$ & $65.5 \pm 7.0$ & 0.1819 \\
Lumbar spine BMD $\left(\mathrm{g} / \mathrm{cm}^{2}\right)$ & $0.696 \pm 0.111$ & $0.687 \pm 0.103$ & 0.7757 \\
Femoral neck BMD $\left(\mathrm{g} / \mathrm{cm}^{2}\right)$ & $0.550 \pm 0.087$ & $0.542 \pm 0.070$ & 0.7105 \\
Whole-body BMD $\left(\mathrm{g} / \mathrm{cm}^{2}\right)$ & $0.818 \pm 0.075$ & $0.812 \pm 0.047$ & 0.7556 \\
No. of vertebral fractures & $1.2 \pm 1.7$ & $0.3 \pm 0.5$ & 0.0637 \\
Thoracic kyphosis angle (degrees) & $44.2 \pm 14.1$ & $42.9 \pm 12.3$ & 0.7326 \\
Lumbar kyphosis angle (degrees) & $-15.5 \pm 18.2$ & $-23.7 \pm 16.8$ & 0.0977 \\
Thoracic spinal ROM (degrees) & $17.5 \pm 12.8$ & $19.7 \pm 19.7$ & 0.5499 \\
Lumbar spinal ROM (degrees) & $51.3 \pm 17.6$ & $57.3 \pm 14.6$ & 0.2025 \\
Back extensor strength (kg) & $12.9 \pm 6.3$ & $17.3 \pm 6.6$ & 0.0130 \\
\hline
\end{tabular}

Values represent mean $\pm \mathrm{SD}$. BP, patients with back pain; non-BP, patients without back pain; BMD, bone mineral density; ROM, range of motion.

Table 2. Comparison of estimated variables between osteoporotic patients with and without back pain. 


\begin{tabular}{lccc}
\hline & OR & $95 \% \mathrm{CI}$ & $P$ \\
\hline Age (years) & 1.052 & $0.976-1.134$ & 0.1845 \\
Lumbar spine BMD $\left(\mathrm{g} / \mathrm{cm}^{2}\right)$ & 2.044 & $0.015-269.925$ & 0.7741 \\
Femoral neck BMD $\left(\mathrm{g} / \mathrm{cm}^{2}\right)$ & 3.289 & $0.006-1695.221$ & 0.7086 \\
Whole body BMD $\left(\mathrm{g} / \mathrm{cm}^{2}\right)$ & 3.275 & $0.002-5461.831$ & 0.7540 \\
No. of vertebral fractures & 2.107 & $0.949-4.680$ & 0.0670 \\
Thoracic kyphosis angle (degrees) & 1.007 & $0.969-1.046$ & 0.7308 \\
Lumbar kyphosis angle (degrees) & 1.033 & $0.994-1.074$ & 0.0958 \\
Thoracic spinal ROM (degrees) & 0.988 & $0.951-1.027$ & 0.5475 \\
Lumbar spinal ROM (degrees) & 0.980 & $0.951-1.011$ & 0.2033 \\
Back extensor strength (kg) & 0.906 & $0.835-0.982$ & 0.0166 \\
\hline
\end{tabular}

$\mathrm{OR}$, odds ratio; $\mathrm{CI}$, confidence interval; $\mathrm{BMD}$, bone mineral density; $\mathrm{ROM}$, range of motion.

Table 3. Univariate logistic regression analysis for back pain in patients with osteoporosis $(n=174)$.

\begin{tabular}{lcc}
\hline & Correlation coefficient $(r)$ & $P$ \\
\hline Age (years) & 0.118 & 0.1391 \\
Lumbar spine BMD $\left(\mathrm{g} / \mathrm{cm}^{2}\right)$ & -0.089 & 0.2643 \\
Femoral neck BMD $\left(\mathrm{g} / \mathrm{cm}^{2}\right)$ & -0.090 & 0.2583 \\
Whole body BMD $\left(\mathrm{g} / \mathrm{cm}^{2}\right)$ & -0.097 & 0.2258 \\
No. of vertebral fractures & 0.171 & 0.0312 \\
Thoracic kyphosis angle (degree) & -0.043 & 0.5892 \\
Lumbar kyphosis angle (degree) & 0.139 & 0.0803 \\
Thoracic spinal ROM (degree) & -0.109 & 0.1707 \\
Lumbar spinal ROM (degree) & -0.264 & 0.0007 \\
Back extensor strength $(\mathrm{kg})$ & -0.268 & 0.0006 \\
\hline
\end{tabular}

*Pain intensity ranged from 0 (no pain) to 20 (worst pain) was calculated from 20 minus estimated pain domain score of JOQOL. BMD, bone mineral density; ROM, range of motion.

Table 4. Correlations between pain intensity* and estimated variables in patients with osteoporosis and back pain $(n=159)$.

\begin{tabular}{lcc}
\hline & Coefficient $(r)$ & $P$ \\
\hline Intercept & 11.238 & $<0.0001$ \\
No. of vertebral fractures & 0.132 & 0.4517 \\
Lumbar spinal ROM (degrees) & -0.041 & 0.0179 \\
Back extensor strength (kg) & -0.116 & 0.0142 \\
\hline
\end{tabular}

*Pain intensity ranged from 0 (no pain) to 20 (worst pain), calculated as 20 minus the estimated pain domain score of JOQOL. ROM, range of motion.

Table 5. Multiple regression analysis for pain intensity* in patients with osteoporosis and back pain $(n=159)$. 


\section{Discussion}

\subsection{Prevalence of back pain}

Back pain is a major source of morbidity among patients with osteoporosis. Osteoporotic vertebral fractures usually cause acute, disabling, painful episodes at the fracture site. Such acute back pain subsides with fracture healing. However, after the fracture heals, the resulting increase in spinal kyphosis is likely to cause chronic back pain (Francis et al., 2008; Satoh et al., 1988). Increased spinal kyphosis is likely to induce abnormal stress on the supporting structures of the spinal column and may cause chronic back pain that usually develops while standing, walking, or doing other normal daily activities (Satoh et al., 1988). The back pain evaluated in the present study was considered to be chronic, because patients with documented vertebral fracture within the preceding 6 months were not included.

The prevalence of back pain, particularly chronic back pain, in patients with osteoporosis has not been fully investigated. Cockerill et al. (Cockerill et al., 2000) reported that the prevalence of back pain in the current and past year for women aged 50 years and over was significantly higher in women with single lumbar vertebral deformities $(51.4 \%$ and $72.6 \%$, respectively) than in women without vertebral deformity (39\% and $60.6 \%$, respectively) $(\mathrm{p}<0.05)$. Jacobs et al. (Jacobs et al., 2006) undertook a longitudinal study of 277 elderly subjects, finding that the prevalence of chronic back pain increased from $44 \%$ to $58 \%$ at ages 70 and 77 years, respectively, and this pain was associated with female sex at age 70 years and osteoporosis at age 77 years. More recently, Kuroda et al. (Kuroda et al., 2009) reported that back pain was observed in $28 \%$ of 818 Japanese postmenopausal women aged over 40 years (mean, 62.1 years) who visited their practitioner, and this back pain was associated with osteoporosis and vertebral fractures. In the present study, the prevalence of clinically relevant back pain was $91.4 \%$. This percentage is higher than previously reported prevalences of back pain in osteoporosis (28-72.6\%) (Cockerill et al., 2000; Jacobs et al., 2006; Kuroda et al., 2009), probably because all patients enrolled in the present study were visitors to an orthopedic clinic and might have had more musculoskeletal symptoms.

\subsection{Factors associated with back pain and pain intensity}

Previous studies have shown that vertebral fractures are associated with back pain and disability, with the strength of these associations increasing with the number and severity of fractures (Ettinger et al., 1992; Huang et al., 1996; Matthis et al., 1998). Increased spinal kyphosis caused by vertebral fractures is also known to induce back pain and disability in patients with osteoporosis (Miyakoshi et al., 2003a). In the present study, the number of vertebral fractures and angles of lumbar kyphosis tended to be higher in patients with back pain than in those without back pain, but no significant differences were identified ( $p=0.0637$ and $p=0.0977$, respectively). However, in patients with back pain, the present study also showed a significant positive correlation between number of vertebral fractures and pain intensity $(\mathrm{r}=0.171, \mathrm{p}=0.0312)$.

An important association between back pain and back extensor strength in patients with osteoporosis is indicated from the present study. Back extensor strength was significantly lower in patients with back pain compared to those without back pain, but other factors we evaluated showed no significant differences between groups. In addition, among patients with back pain, multiple regression analysis for pain intensity revealed back extensor strength and lumbar spinal ROM as significantly associated with pain intensity. Decreased back extensor strength may thus represent the most important factor contributing to back 
pain and pain intensity in patients with osteoporosis. Subjects on acute back pain due to fresh vertebral fractures maybe could not perform the back extensor strength tests as good as non-acute pain subjects. However, because the back pain evaluated in the present study was considered to be chronic, all the patients could perform the strength tests without increasing the pain. Thus, we concluded that the weakness of back extensor is a very important factor for chronic back pain in patients with osteoporosis.

Back extensor strength reportedly shows a significant relation with spinal mobility (Miyakoshi et al., 2005), and decreased mobility of the spine is thought to lead to increased kyphosis and weakness of the paravertebral muscles, as well as the development of impaired physical function (Burger et al., 1997). Decreased back extensor strength may thus reduce mobility of the lumbar spine, and a less mobile lumbar spine may cause stiffness of the back muscles, resulting in back pain. As muscle strength is determined largely by muscle mass, particularly the cross-sectional area of muscle (Maughan, 2005), and because the muscle cross-sectional area of back extensor muscles (the erector spinae group) is larger at the lumbar spine level than at the thoracic spine level (Marras et al., 2001), total back extensor strength is largely influenced by lumbar extensor muscles rather than thoracic extensor muscles. The results of the present study are not inconsistent with this anatomical background. Weakness of the back extensor muscles, particularly the lumbar extensor muscles, is thought to be responsible for lumbar spinal mobility.

\subsection{Other possible factors contributing to back pain in osteoporosis}

The present study focused on back pain and multiple spinal factors in patients with osteoporosis. However, the etiology of back pain is more complex and more multifactorial than could be examined in this study. Prevalence of musculoskeletal pain is also known to be associated with various measures of socio-economic status, as well as comorbidities (Thomas et al., 1999; Woo et al., 2009). Severity of pain may also be influenced by psychological factors (Woo et al., 2009). In addition, elderly patients with osteoporosis sometimes show other painful spinal disorders such as spondylosis to varying extents (Miyakoshi et al., 2003b). Findings in the present study might also have been influenced, at least in part, by factors other than osteoporosis.

\subsection{Study limitations}

Limitations of the present study should be noted. First, the number of subjects in the present study was much smaller than in previous studies evaluating the prevalence of back pain (Cockerill et al., 2000; Jacobs et al., 2006; Kuroda et al., 2009). However, we would like to emphasize that this is the first study to simultaneously evaluate back pain and multiple spinal factors in patients with osteoporosis. Second, data could not be obtained from severely kyphotic patients with established osteoporosis who were too disabled to lie in a prone position because of increased back pain in this position. This was because the dynamometer for measuring back extensor strength in the present study needed the patient to lie in a prone position. Therefore, the results of the present study might be considered for patients with mild or moderate spinal deformity.

\section{Conclusions}

In conclusion, the prevalence of back pain among patients with postmenopausal osteoporosis $\geq 50$ years old who visited their practitioner was $91.4 \%$. Back extensor strength 
was significantly lower in patients with back pain compared to those without back pain. Among subjects with back pain, intensity of back pain showed significant relationships with decreased back extensor strength and limited lumbar spinal mobility.

\section{Acknowledgement}

We wish to thank all the staff of Joto Orthopedic Clinic for their valuable assistance in conducting the study.

\section{References}

Burger, H.; Van Daele, P.L.; Grashuis, K.; Hofman, A.; Grobbee, D.E.; Schütte, H.E.; Birkenhäger, J.C. \& Pols, H.A. (1997). Vertebral deformities and functional impairment in men and women. Journal of Bone and Mineral Research, Vol.12, No.1, (January 1997), pp.152-157, ISSN 0884-0431

Cockerill, W.; Ismail, A.A.; Cooper, C.; Matthis, C.; Raspe, H.; Silman, A.J. \& O'Neill, T.W. (2000). Does location of vertebral deformity within the spine influence back pain and disability? European Vertebral Osteoporosis Study (EVOS) Group. Annals of the Rheumatic Diseases, Vol.59, No.5, (May 2000), pp.368-371, ISSN 0003-4967

Djurasovic. M. \& Glassman, S.D. (2007). Correlation of radiographic and clinical findings in spinal deformities. Neurosurgery Clinics of North America, Vol.18, No.2, (April 2007), pp.223-227, ISSN 1042-3680

Edmond, S.L. \& Felson, D.T. (2000). Prevalence of back symptoms in elders. The Journal of Rheumatology, Vol.27, No.1, (January 2000), pp.220-225, ISSN 0315-162X

Ettinger, B.; Black, D.M.; Nevitt, M.C.; Rundle, A.C.; Cauley, J.A.; Cummings, S.R. \& Genant, H.K. (1992). Contribution of vertebral deformities to chronic back pain and disability. The Study of Osteoporotic Fractures Research Group. J Bone Miner Res, Vol.7, No.4, (April 1992), pp.449-456, ISSN 0884-0431

Francis, R.M.; Aspray, T.J.; Hide, G.; Sutcliffe, A.M. \& Wilkinson, P. (2008). Back pain in osteoporotic vertebral fractures. Osteoporosis International, Vol.19, No.7, (July 2008), pp.895-903, ISSN 0937-941X

Glassman, S.D.; Bridwell, K.; Dimar, J.R.; Horton, W.; Berven, S. \& Schwab F. (2005). The impact of positive sagittal balance in adult spinal deformity. Spine (Phila Pa 1976), Vol.30, No.18, (September 2005), 2024-2029, ISSN 0362-2436

Hongo, M.; Itoi, E.; Sinaki, M.; Miyakoshi, N.; Shimada, Y.; Maekawa, S.; Okada, K. \& Mizutani, Y. (2007). Effect of low-intensity back exercise on quality of life and back extensor strength in patients with osteoporosis: a randomized controlled trial. Osteoporosis International, Vol.18, No.10, (October 2007), pp.1389-1395, ISSN 0937941X

Huang, C.; Ross, P.D, \& Wasnich, R.D. (1996). Vertebral fractures and other predictors of back pain among older women. Journal of Bone and Mineral Research, Vol.11, No.7, (July 1996), pp.1026-1032, ISSN 0884-0431

Hübscher, M.; Vogt, L.; Schmidt. K.; Fink, M. \& Banzer, W. (2010). Perceived pain, fear of falling and physical function in women with osteoporosis. Gait \& Posture, Vol.32, No.3, (July 2010), pp.383-385, ISSN 0966-6362 
Jacobs, J.M.; Hammerman-Rozenberg, R.; Cohen, A. \& Stessman, J. (2006). Chronic back pain among the elderly: prevalence, associations, and predictors. Spine (Phila Pa 1976), Vol.31, No.7, (April 2006), pp.E203-207, ISSN 0362-2436

Kasukawa, Y.; Miyakoshi, N.; Hongo, M.; Ishikawa, Y.; Noguchi, H.; Kamo, K.; Sasaki, H.; Murata, K. \& Shimada, Y. (2010). Relationships between falls, spinal curvature, spinal mobility and back extensor strength in elderly people. Journal of Bone and Mineral Metabolism, Vol.28, No.1, (January 2010), pp.82-87, ISSN 0914-8779

Kumamoto, K.; Nakamura, T.; Suzuki, T.; Gorai, I.; Fujinawa, O.; Ohta, H.; Shiraki, M.; Yoh, K.; Fujiwara, S.; Endo, N. \& Matsumoto, T. (2010). Validation of the Japanese Osteoporosis Quality of Life Questionnaire. Journal of Bone and Mineral Metabolism, Vol.28, No.1, (January 2010), pp.1-7, ISSN 0914-8779

Kuroda, T.; Shiraki, M.; Tanaka, S.; Shiraki, Y.; Narusawa, K. \& Nakamura, T. (2009). The relationship between back pain and future vertebral fracture in postmenopausal women. Spine (Phila Pa 1976), Vol.34, No.18, (August 2009), pp.1984-1989, ISSN 0362-2436

Lavsky-Shulan, M.; Wallace, R.B.; Kohout, F.J.; Lemke, J.H.; Morris, M.C. \& Smith, I.M. (1985). Prevalence and functional correlates of low back pain in the elderly: the Iowa 65+ Rural Health Study. Journal of the American Geriatrics Society, Vol.33, No.1, (January 1985), pp.23-28, ISSN 0002-8614

Limburg, P.J.; Sinaki, M.; Rogers, J.W.; Caskey, P.E. \& Pierskalla, B.K. (1991). A useful technique for measurement of back strength in osteoporotic and elderly patients. Mayo Clinic Proceedings, Vol.66, No.1, (January 1991), pp.39-44, ISSN 0025-6196

Liu-Ambrose, T.; Eng, J.J.; Khan, K.M.; Mallinson, A.; Carter, N.D. \& McKay, H.A. (2002). The influence of back pain on balance and functional mobility in 65- to 75-year-old women with osteoporosis. Osteoporosis International, Vol.13, No.11, (November 2002), pp. 868-873, ISSN 0937-941X

Mannion, A.F.; Knecht, K.; Balaban, G.; Dvorak, J. \& Grob, D. (2004). A new skin-surface device for measuring the curvature and global and segmental ranges of motion of the spine: reliability of measurements and comparison with data reviewed from the literature. European Spine Journal, Vol.13, No.2, (March 2004), pp.122-136, ISSN 0940-6719

March, L.M.; Brnabic, A.J.; Skinner, J.C.; Schwarz, J.M.; Finnegan, T.; Druce, J. \& Brooks, P.M. (1998). Musculoskeletal disability among elderly people in the community. The Medical Journal of Australia, Vol.168, No.9, (May 1998), pp.439-442, ISSN 0025$729 \mathrm{X}$

Marras, W.S.; Jorgensen, M.J.; Granata, K.P. \& Wiand, B. (2001). Female and male trunk geometry: size and prediction of the spine loading trunk muscles derived from MRI. Clinical Biomechanics (Bristol, Avon), Vol.16, No.1, (January 2001), pp.38-46, ISSN 0268-0033

Matthis, C.; Weber, U.; O'Neill, T.W. \& Raspe, H. (1998). Health impact associated with vertebral deformities: results from the European Vertebral Osteoporosis Study (EVOS). Osteoporosis International, Vol.8, No.4, (August 1998), pp.364-372, ISSN 0937-941X

Maughan, R.J. (2005). The limits of human athletic performance. Annals of Transplantation, Vol.10, No.4, (October-December 2005), pp.52-54, ISSN 1425-9524 
Miyakoshi, N.; Hongo, M.; Maekawa, S.; Ishikawa, Y.; Shimada, Y. \& Itoi, E. (2007) Back extensor strength and lumbar spinal mobility are predictors of quality of life in patients with postmenopausal osteoporosis. Osteoporosis International, Vol.18, No.10, (October 2007), pp. 1397-1403, ISSN 0937-941X

Miyakoshi, N.; Hongo, M.; Maekawa, S.; Ishikawa, Y.; Shimada, Y.; Okada, K. \& Itoi, E. (2005). Factors related to spinal mobility in patients with postmenopausal osteoporosis. Osteoporosis International, Vol.16, No.12, (December 2005), pp.18711874, ISSN 0937-941X

Miyakoshi, N.; Hongo, M.; Tani, T.; Maekawa, S.; Shimada, Y. \& Itoi, E. (2004). Relationship between spinal mobility and quality of life in patients with osteoporosis. Osteoporosis Japan, Vol.12, No.1, (January 2004), pp.143-146, ISSN 0919-6307 (in Japanese)

Miyakoshi, N.; Itoi, E.; Kobayashi, M. \& Kodama, H. (2003a). Impact of postural deformities and spinal mobility on quality of life in postmenopausal osteoporosis. Osteoporosis International, Vol.14, No.12, (December 2003), pp.1007-1012, ISSN 0937-941X

Miyakoshi, N.; Itoi, E.; Murai, H.; Wakabayashi, I.; Ito, H. \& Minato, T. (2003b). Inverse relation between osteoporosis and spondylosis in postmenopausal women as evaluated by bone mineral density and semiquantitative scoring of spinal degeneration. Spine (Phila Pa 1976), Vol.28, No.5, (March 2003), pp.492-495, ISSN 0362-2436

Miyakoshi, N.; Kasukawa, Y.; Ishikawa, Y.; Nozaka, K. \& Shimada, Y. (2010). Spinal alignment and mobility in subjects with chronic low back pain with walking disturbance: a community-dwelling study. The Tohoku Journal of Experimental Medicine, Vol.221, No.1, (January 2010), pp.53-59, ISSN 0040-8727

Nevitt, M.C.; Ettinger, B.; Black, D.M.; Stone, K.; Jamal, S.A.; Ensrud, K.; Segal, M.; Genant, H.K. \& Cummings, S.R. (1998). The association of radiographically detected vertebral fractures with back pain and function: a prospective study. Annals of internal medicine, Vol.128, No.10, (May 1998), pp. 793-800, ISSN 0003-4819

Orimo, H.; Hayashi, Y.; Fukunaga, M.; Sone, T.; Fujiwara, S.; Shiraki, M.; Kushida, K.; Miyamoto, S.; Soen, S.; Nishimura, J.; Oh-Hashi, Y.; Hosoi, T.; Gorai, I.; Tanaka, H.; Igai, T. \& Kishimoto, H. (2001). Diagnostic criteria for primary osteoporosis: year 2000 revision. Journal of Bone and Mineral Metabolism, Vol.19, No.6, (September 2001), pp.331-337, ISSN 0914-8779.

Orimo, H.; Shiraki, M.; Hayashi, Y.; Hoshino, T.; Onaya, T.; Miyazaki, S.; Kurosawa, H.; Nakamura, T. \& Ogawa, N. (1994). Effects of 1 alpha-hydroxyvitamin D3 on lumbar bone mineral density and vertebral fractures in patients with postmenopausal osteoporosis. Calcified Tissue International, Vol.54, No.5, (May 1994), pp.370-376, ISSN 0171-967X

Post, R.B. \& Leferink, V.J. (2004). Spinal mobility: sagittal range of motion measured with the SpinalMouse, a new non-invasive device. Archives of Orthopaedic and Trauma Surgery, Vol.124, No.3, (April 2004), pp.187-192. ISSN 0936-8051

Satoh, K.; Kasama, F.; Itoi, E.; Tanuma, S. \& Wakamatsu, E. (1988). Clinical features of spinal osteoporosis: spinal deformity and pertinent back pain. Contemporary Orthopaedics, Vol.16, No.3 , (March 1988), pp.23-30, ISSN 0194-8458

Takahashi, H.; Iwaya, C.; Iba, K.; Gorai, I., Suzuki, T.; Hayashi, Y.; Fujinawa, S.; Yamazaki, K. \& Endo, N (2001). The Japanese Osteoporosis QOL Questionnaire (JOQOL): 2000 
edition. Journal of Japanese Society for Bone and Mineral Research, Vol.18, No.3, (January 2001), pp.85-101, ISSN 0910-0067 (in Japanese)

Thomas, E.; Silman, A.J.; Croft, P.R.; Papageorgiou, A.C.; Jayson, M.I. \& Macfarlane, G.J. (1999). Predicting who develops chronic low back pain in primary care: a prospective study. British Medical Journal, Vol.318, No.7199, (June 1999), pp.16621667, ISSN 0959-8138

Ulivieri, FM. (2007). Back pain treatment in post-menopausal osteoporosis with vertebral fractures. Aging Clinical and Experimental Research, Vol.19, No.3 Suppl., (June 2007), pp.21-23, ISSN 1594-0667

Woo, J.; Leung, J. \& Lau, E. (2009). Prevalence and correlates of musculoskeletal pain in Chinese elderly and the impact on 4-year physical function and quality of life. Public Health, Vol.123, No.8, (August 2009), pp.549-556, ISSN 0033-3506 


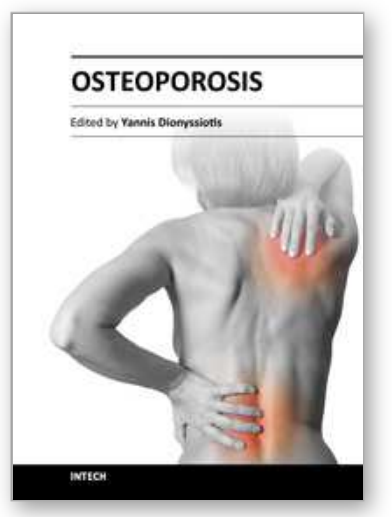

\author{
Osteoporosis \\ Edited by PhD. Yannis Dionyssiotis
}

ISBN 978-953-51-0026-3

Hard cover, 864 pages

Publisher InTech

Published online 24, February, 2012

Published in print edition February, 2012

Osteoporosis is a public health issue worldwide. During the last few years, progress has been made concerning the knowledge of the pathophysiological mechanism of the disease. Sophisticated technologies have added important information in bone mineral density measurements and, additionally, geometrical and mechanical properties of bone. New bone indices have been developed from biochemical and hormonal measurements in order to investigate bone metabolism. Although it is clear that drugs are an essential element of the therapy, beyond medication there are other interventions in the management of the disease. Prevention of osteoporosis starts in young ages and continues during aging in order to prevent fractures associated with impaired quality of life, physical decline, mortality, and high cost for the health system. A number of different specialties are holding the scientific knowledge in osteoporosis. For this reason, we have collected papers from scientific departments all over the world for this book. The book includes up-to-date information about basics of bones, epidemiological data, diagnosis and assessment of osteoporosis, secondary osteoporosis, pediatric issues, prevention and treatment strategies, and research papers from osteoporotic fields.

\title{
How to reference
}

In order to correctly reference this scholarly work, feel free to copy and paste the following:

Naohisa Miyakoshi, Michio Hongo and Yoichi Shimada (2012). Prevalence of Back Pain in Postmenopausal Osteoporosis and Associations with Multiple Spinal Factors, Osteoporosis, PhD. Yannis Dionyssiotis (Ed.), ISBN: 978-953-51-0026-3, InTech, Available from: http://www.intechopen.com/books/osteoporosis/prevalenceof-back-pain-in-postmenopausal-osteoporosis-and-associations-with-multiple-spinal-factors

\section{INTECH}

open science | open minds

\section{InTech Europe}

University Campus STeP Ri

Slavka Krautzeka 83/A

51000 Rijeka, Croatia

Phone: +385 (51) 770447

Fax: +385 (51) 686166

www.intechopen.com

\section{InTech China}

Unit 405, Office Block, Hotel Equatorial Shanghai

No.65, Yan An Road (West), Shanghai, 200040, China

中国上海市延安西路65号上海国际贵都大饭店办公楼 405 单元

Phone: $+86-21-62489820$

Fax: +86-21-62489821 
(C) 2012 The Author(s). Licensee IntechOpen. This is an open access article distributed under the terms of the Creative Commons Attribution 3.0 License, which permits unrestricted use, distribution, and reproduction in any medium, provided the original work is properly cited. 